\title{
External costs of electricity generation
}

\author{
Rainer Friedrich and Alfred Voss
}

\begin{abstract}
Internalizing of external costs leads to a better allocation of economic resources, and so to an improvement of welfare. However, if the external effects that can be quantified and monetized are added to the internal costs, the cost relations between different electricity generation systems are not necessarily changed. Of course, the underlying assumptions (like dose-response relationships) are very uncertain, and some external effects that could be important cannot be monetized. However, statements of other authors that with certainty quantifiable external effects are high (of the order of magnitude of the internal costs) can be relativized.
\end{abstract}

Keywords: External costs; Electricity generation; External effects

Energy conversion processes - like other processes have undesirable side effects especially with damage to the environment. The costs which originate from these effects are often not at all or only partly considered in the producer's bill of costs. The misallocation of scarce resources may be the consequence, since plant operators come to decisions that are optimal for them but may not be optimal for society. This is in opposition to the aim of maximizing social welfare.

These external costs should therefore be internalized ie they should be paid for by whoever produces them. Of course, this means that it must be possible to identify, quantify and monetize the external effects.

In this connection a first rough estimate of external costs compiled by Hohmeyer has gained great attention, at least in Germany, as the external costs of electricity production are calculated to be of the same order of magnitude as internal electricity production costs. ${ }^{1}$ However, a closer look at the study

The authors are with the Institut Für Energiewirtschaft und Rationelle Energieanwendung, Hessbrühlstrasse 49a D-7000 Stuttgart-80, Germany. reveals that the methodologies and data used are in our opinion unsuitable, and the estimates of external costs derived from them are too high.

In order to be able to ascertain the order of magnitude, and thus the importance of quantifiable external effects or costs, we have made our own estimate, and the results are described below. (A more detailed description may be found in Friedrich et al). ${ }^{2}$ The results refer to the situation in Germany and are not necessarily applicable to other countries.

\section{Definition}

'External costs' of electricity generation are defined here as all negative technology related effects involved in electricity generation - including antecedent and subsequent process steps such as the erection and dismantling of power plants, the acquisition and transport of energy resources, and the disposal of wastes - which are not paid for by the producer but by the general public or other parties.

'Social costs' are all the costs incurred in the generation of electricity ie the total of external costs and the costs borne by the producer. Social costs do not include taxes, as these are transferred rather than expended. This article looks in detail at the electricity generation options of coal and nuclear power stations, wind energy conversion and photovoltaic systems.

The aim of the study is to estimate the external costs of these power generation systems - as far as they can be quantified and monetized given our present state of knowledge - and to examine whether the internalization of these external costs would alter the competitive position of the options investigated, especially of renewable energy technologies (from an economic point of view) now or in the foreseeable future, say by the year 2000 . In order to do this, the external costs of new systems put into operation in the years in question (1988 or 2000) must be calculated and included in the comparison. The costs incurred during the lifetime of the system, including erection and dismantling, are indicated in the form of average mathematically calculated finan- 
cial costs per kilowatt hour generated. All prices, costs and increases in price are quoted in real terms in monetary value for the year 1988 , with a real discounting rate of $4 \%$ per annum.

A comparison between new systems on the basis of renewable energy resources with the average power station set up in 1982 (as attempted in Hohmeyer) appears to be an inadequate approach to the problem. ${ }^{3}$

The following sections deal individually with some of the external effects contributing to external costs which can currently be quantified, starting with damage to the natural environment through air pollution.

\section{Forest damage}

Most of the problems incurred when quantifying external effects can be demonstrated by treating the exemplary case of damage to forests caused by environmental pollution.

The evaluation of external costs attributed to the damage observed to plants and, in particular, to forests requires the following principal steps:

- the determination of the contribution of a source of emissions to existing ambient concentrations of air pollutants;

- the calculation of the surplus damage caused by one additional unit of ambient air concentration of pollutants;

- the assessment of a monetary value equivalent to the unit damage.

However, none of these steps can be accomplished with sufficient accuracy, on the basis of present knowledge, for the following reasons:

- Spreading and chemical transformations of pollutants can only be described in a very rough manner.

- The damage function, which shows the relationship between the ambient air concentration of pollutants and the damage, is not known.

- Commonly accepted methods to quantify damage types such as the reduced value of forests as leisure areas are not available.

Nevertheless, estimates of the monetary values of forest damage have been made by Ewers. ${ }^{4}$ As the quantitative correlation between forest damage and the supposed cause, namely air pollution, is not known, Ewers interviewed experts on the future development of different parameters affecting forest damage eg distribution of the various degrees of damage or reduction in tree growth under specific air pollution conditions (scenarios). Using a calculated interest rate of $2 \%$, he estimated average damage of 1984 DM5.5 billion pa in the case of a so-called 'trend scenario' in which the emissions drop from 1984 onwards, and 1984 DM8.8 billion pa in the case of a so-called 'status quo scenario', which assumes a constant level of emissions at the 1980 level. More than half of this damage is incurred in leisure and recreation activities. for example through loss of earnings in the tourist industry or through reduced recreational utilization of forests, although the monetization of this latter parameter is very difficult.

In the absence of further knowledge, the forest damage determined in this way is attributed globally and in its entirety to air pollution, as neither the actual extent to which air pollution causes forest damage nor the role played by the individual pollutants is known. For this reason it may be regarded as the upper limit of possible forest damage through air pollution.

In order to convert the different air pollutants into a common unit of 'kilogram pollutant equivalent', they are weighted in relation to the maximum permissible concentrations at a place of work (MAK values). The forest damage is first converted to the 1988 price basis and then divided by the weighted annual emissions in the corresponding emission scenario. The specific damage per unit pollutant equivalent is somewhat higher in the trend scenario than in the status quo scenario, but as the trend scenario more accurately reflects probable future emission developments, this higher value is used and multiplied in the next step by the specific emissions per kilowatt hour of electricity of a modern coal power station with desulphurization and DENOX systems and a dust filter, using the following emission factors: $0.8 \mathrm{~g} \mathrm{SO}_{2} / \mathrm{kWh}_{\mathrm{cl}} ; 0.67 \mathrm{~g} \mathrm{NO}_{x} / \mathrm{kWh}_{\mathrm{el}}$; $0.06 \mathrm{~g}$ dust $/ \mathrm{kWh}_{\mathrm{el}} ; 0.14 \mathrm{~g} \mathrm{CO} / \mathrm{kWh}_{\mathrm{el}}$; and $0.03 \mathrm{~g}$ hydrocarbons $/ \mathrm{kWh}_{\mathrm{cl}}$. Using this estimate the external costs of forest damage caused by electricity in coal power stations are $\mathrm{Pf} 0.19 / \mathrm{kWh}_{\mathrm{cl}}$.

\section{Agriculture and gardening, fauna}

Only very rough estimates of the damage caused by air pollution are available for Germany. Wicke estimates agricultural losses of at least 1988 DM100 million pa for animal farming, based on a study by the North Rhine Westphalia State Institute of Emission and Land Utilization Protection which calculated a loss of meat and milk of 1964 DM17 million pa for North Rhine Westphalia (a state of FR Germany) due to air pollution in $1964 .^{5}$ 
Heinz calculates a reduction in crop yield through air pollution of 1977 DM125 million pa. ${ }^{6}$ This estimate is based on a $10 \%$ drop in the yield of very sensitive plants (alfalfa, clover, fruit) through air pollution in most affected areas and a 5\% drop for sensitive plants (oats, barley, rye, wheat, pulses). Wicke considers these estimates to be too low, claiming that damage also occurs outside the most affected areas. ${ }^{7}$ His estimate puts the total damage at 1986 DM1 billion pa. Further calculations are based on this figure.

On the basis of these estimates a modern coal power station would incur external costs of $\mathrm{Pf} 0.002 /$ $\mathrm{kWh}_{\mathrm{el}}$ for losses in animal farming and Pf0.021/ $\mathrm{kWh}_{\mathrm{cl}}$ for reduced harvests. These figures take no account of wild plants as quantitative estimates are not available.

\section{Material damage}

Heinz has estimated the extent of material damage caused by air pollution, including more frequent painting and cleaning of building facades, windows, doors, metal railings etc, replacement of guttering, better and more frequent coating of steel components eg on road and railway bridges, overhead railway pylons and electricity pylons in affected areas. ${ }^{8} \mathrm{He}$ calculates costs of 1983 DM2.30 billion pa for this damage, the majority being caused by the more frequent painting of buildings. This figure is used as the lower limit for estimating material damage. It does not include damage to works of art or monuments. Both Heinz and Wicke put these costs at a minimum of several times DM10 million pa.

The costs incurred through increased textile cleaning and new wallpapering and the possible damage in less affected areas are also left out of consideration. In order to allow for these unknown factors, the upper limit for material damage through air pollution is put at DM4.2 billion pa. ${ }^{9}$

The external costs as a result of material damage caused by coal power stations thus amount to Pf0.047-0.082/kWh $\mathrm{kl}_{\mathrm{el}}$.

\section{Effects on human health}

Electricity generating systems may affect human health in a number of different ways. Detrimental effects stem from routine emission eg of toxic agents released during the operation of a coal fired power plant as well as from accidental situations such as a major accident at a nuclear site or a coal mine disaster (major nuclear accidents are treated separately in the next section). Some of the effects or
Table 1. Risks of electricity generation from coal per $\mathrm{GW}$ per year.

\begin{tabular}{|c|c|c|}
\hline & $\begin{array}{l}\text { Deaths } \\
\text { (number/GWa } \mathbf{a}_{\mathrm{el}} \text { ) }\end{array}$ & $\begin{array}{l}\text { Accidents illness } \\
\text { (working days } \\
\text { lost per } \mathrm{GWa}_{\mathrm{e}} \text { ) }\end{array}$ \\
\hline \multicolumn{3}{|l|}{ Occupational risks } \\
\hline Coal mining & 3.2 & 14800 \\
\hline Transport & 0.19 & 1110 \\
\hline Erection of plants & 0.18 & 1140 \\
\hline Operation of plants & 0.02 & 150 \\
\hline Public risks & & Number \\
\hline Transport & 0.06 & 0.06 \\
\hline $\mathrm{SO}_{2}$ emissions & $0-23$ & $0-84$ \\
\hline Radioisotopes & 0.15 & 0.3 \\
\hline Erection & 0.01 & 0.38 \\
\hline Disposal & 0.1 & 5.24 \\
\hline Total & $3.9-27.0$ & \\
\hline
\end{tabular}

health risks can be quantified with rather high accuracy, as is the case for fatal occupational accidents in coal mines or during the construction of wind energy converters. Other effects such as respiratory diseases caused by emitted air pollutants lack quantification as dose-response functions are either lacking or controversial.

In order to estimate external health costs, the results of a study by Kallenbach and Thöne were used. ${ }^{10}$ In this study the occupational and public health risks of different power generation options were determined, including not only operating risks but also those entailed in the erection of the plant, the acquisition and transport of the fuels and the treatment and disposal of residues. Apart from the effects of air pollution, those of radioactive emissions in normal operation were also taken into account.

Table 1 shows the health risks of power stations using domestic coal. The high risk in coal mining and the large degree of uncertainty with regard to air pollution risks are both clearly evident.

Based on these figures two types of costs are taken into account:

Sickness costs are regarded as the costs of medical treatment for sickness not caused occupationally, as the sickness costs of occupational illness and accidents are already internalized via the insurance companies and employers' liability insurance associations.

In addition, the economic losses due to the fact that the ill health of the person caused by electricity generation prevents him/her from participating actively in the economic production process are quantified at DM78 600 per lost working year for persons in employment and DM33 000 per year for others. The lost work time varies depending on the type of 
illness and was determined on the basis of statistical data.

The following external costs of health risks can be estimated for the four electricity producing systems using this approach:
$0.18 \mathrm{Pf} / \mathrm{kWh}_{\mathrm{cl}}$ for coal power stations
0.01-0.06 $\mathrm{Pf} / \mathrm{kWh}$ for nuclear power stations (normal operation)
$0.02-0.05 \mathrm{Pf} / \mathrm{kWh}_{\mathrm{cl}}$ for wind converters
0.06-0.09 Pf/kWh $\mathrm{kl}$ for photovoltaic arrays

In the case of the wind and photovoltaic generators these costs are mainly incurred in conjunction with the erection of the systems. The figures do not include the human suffering caused by accidents and illness, as there were no commonly accepted means of monetizing such parameters at the time of the performance of the study and there are still no values available for Germany. If US $\$ 2.9$ million were used as value of a statistical life (taken from a US study from Marin and Psacharopoulos), ${ }^{11}$ external costs of Pf0.2-1.3/kWh $\mathrm{kl}_{\mathrm{el}}$ would result for coal fired stations. The results for the other three techniques would be between $\mathrm{Pf} 0.01$ and $0.10 \mathrm{kWh}_{\mathrm{el}}$. These numbers are taken to calculate the upper values of the range of results shown in Tables 3,6 and 7 .

\section{Effects of major reactor accidents}

To calculate the effects of major reactor accidents, the damage occurring through the different types of possible accidents must be quantified. This damage is then weighted in accordance with the probability of each of these accidents actually occurring. The applicable monetary risk of major reactor accidents is the sum of all weighted damage. Account must also be taken of the fact that damage up to DM500 million per accident outside the plant is covered by statutory insurance and is thus already internalized in the electricity generation costs.

As there is no study presently available which determines the monetized risks in Germany in the manner described above, a US study by Burke, Aldrich and Rasmussen is used to make a first rough estimate of the order of magnitude of this accident damage. ${ }^{12}$ Based on the data of Burke et al, the external costs for accidents in nuclear power plants come to between Pf0.008/kWh and 0.07/kWh. Both the upper and lower limits estimated by Burke et al have been raised to allow for the fact that the sites in Germany possess different characteristics from those in the USA, eg a higher population density. It should nevertheless be pointed out that the results of
Burke et al can only be transferred to a limited extent to Germany. Calculations taking account of recent results of reactor safety research (risk study phase B) are needed for the external accident costs to be determined with greater accuracy.

However, it is still more or less disputed how often the occurrence of a given radiological source term must be expected per year of operation. This is one reason why the overall risk of nuclear accidents in Germany cannot be quantified today without any doubt. Futher investigations in that field are desirable.

\section{Economic effects}

Some authors estimate the different effects on employment of the various generation systems. ${ }^{13}$ Costs saved on unemployment eg welfare payments, are attributed in the form of external benefits to those technologies with high manpower requirements.

In the view of the authors of this article, however, this procedure is inadequate. While unemployment highlights market adaptation problems, it is by no means a direct consequence of electricity generation. The internalization of savings on unemployment in an electricity generation system would arbitrarily attribute reductions in unemployment to a specific technical system without allowance for the possibility of other utilizations outside the electricity generation sector which might produce greater benefits with the same reduction in unemployment.

It would appear obvious that the use of additional labour to provide additional services or to produce additional goods would be more likely to increase welfare than the substitution of a lower priced electricity generation technology by a labour intensive system which produces the same amount of electricity as the substituted system. To overcome unemployment it is necessary to change the general conditions of the market and not merely to subsidize certain technologies. In addition, the costs on unemployment do not apply in the case of full employment, a situation which could quite easily recur in the future. For these reasons economic effects should not to be regarded as external effects.

In addition, the use of expensive systems of electricity generation does not generally lead to an increase in the number of jobs because the rise in the cost of electricity produces a drop in the domestic demand for goods. An input-output calculation by Karl, for example, shows that the construction of 1100 additional wind converters of $200 \mathrm{~kW}$ each would lead to a negative employment effect of 660 person years during a utilization period of 15 years. ${ }^{14}$ 
Table 2. Public research and development spending (R\&D) in FR Germany.

\begin{tabular}{|c|c|c|}
\hline & $\begin{array}{l}\text { 1960-88 } \\
\text { billion DM } \\
\text { (nominal) }\end{array}$ & $\begin{array}{l}1988 \\
\text { million } \mathrm{DM}^{2}\end{array}$ \\
\hline Coal & 4.7 & 121 \\
\hline Nuclear energy (LWR) ${ }^{b}$ & 11.2 & 646 \\
\hline Wind $^{c}$ & 0.24 & 34 \\
\hline Photovoltaic $^{c}$ & 0.50 & 99 \\
\hline
\end{tabular}

${ }^{a}$ Estimated values. ${ }^{\mathrm{b}} 1968-88$, excluding fusion, fast breeder and high-temperature reactors. " $1974-88$ excluding EC and Bundesländer expenditure.

Source: Values for wind and photovoltaic generated electricity are taken from H. W. Schiffer, Energiemarkt Bundesrepublik, Cologne, 1988.

\section{Costs of utilization of non-renewable resources}

Non-renewable resources such as coal, oil, gas and uranium are only available in finite quantities. As they are likely to be exhausted sometime in the future, there is the question of whether the increasing shortage of these goods as they are used up is allowed for in the market price in order to guarantee optional intertemporal allocation as a means of maximizing welfare. According to the economic theory of natural exhaustible resources the costs of limited resources consist of exploitation costs and using costs. The latter costs are defined as the future loss of the benefit of utilization as a result of the present consumption of these resources. In a perfect market a resource is used up along an optimal extraction curve. The using costs therefore increase with the interest rate (Hotelling rule) ${ }^{15}$ As a result, the actual value of the using costs is the same for all periods. A person using a resource now and investing the proceeds from the utilization has the same benefit as a person who uses the resource later. The extent of the using costs is then determined by the costs of available alternative electricity generation systems (so-called back stop technologies).

In other words, in perfect markets the prices of finite resources include the using costs, so an additional internalizing would not be necessary. However, the possibility cannot be ruled out that the market mechanisms described above are not fully operative if the range of the resources extends to several generations. In that case, future generations benefit from a belated use of a resource, and it is open to debate whether people living now will renounce their own benefit in favour of those living in the future.

Before speculating on the extent to which using costs are contained in today's energy prices, the order of magnitude of using costs should be estimated.

According to the World Energy Conference in 1986 a total of 187000 EJ of extractable fossil resources are available, equivalent to a static availability (quotient of the extractable resources and the current world energy consumption) of approximately 600 years. A rough calculation based on back stop technology costs of $1988 \mathrm{DM} 0.8 / \mathrm{kWh}$ and a fossil resource availability of 200 years and with a real discounting rate of $4 \%$ pa gives using costs of approximately $\mathrm{Pf} 0.03 / \mathrm{kWh}_{\mathrm{el}}$ or approximately Pf0.01/ $\mathrm{kWh}_{\text {th }}$ in terms of fuel, according to the Hotelling rule. This figure is so low that it may be contained in present fuel prices.

\section{Public expenditure}

Subsidies and research and development spending are the principal types of public expenditure on specific technologies which do not figure in the electricity generation costs. This expenditure can be considerable.

\section{R\&D expenditure}

Research and development expenditure in the past and on the electricity generation technologies under consideration in 1988 is shown in Table 2.

Expenditure on nuclear energy utilization from 1956 to 1988 amounted to DM25.5 billion of which DM6. 4 billion was on fast breeders, DM2.3 billion on fusion and DM4.2 billion on high temperature reactors. A total of DM11.2 billion is to be allocated to light water reactors, with state revenue from nuclear power station operators of DM1.4 billion deducted from the expenditure. These amounts do not include spending on fundamental nuclear physics research (eg expenditure on high performance accelerators).

The subsequent internalization of funds already spent is not a sensible approach in terms of future investment decisions because the costs already incurred cannot be reversed. Even with a total run down of nuclear energy the funds already spent on nuclear power stations could not be recovered, for example. For this reason, only future expenditure directly concerned with the construction, operation and dismantling of new electricity generation units can be included as external costs, as it is only these costs which can be influenced by today's decisions.

On the other hand, it is quite difficult to allocate expenditure for research and development to individual plants. So, an approximation approach, that 


\begin{tabular}{|c|c|c|c|c|}
\hline \multirow{2}{*}{$\begin{array}{l}\text { Cost } \\
\text { category }\end{array}$} & \multicolumn{4}{|c|}{ Costs $\left(\mathrm{Pf}_{8 s} / \mathrm{kWh}\right)^{\mathrm{a}}$} \\
\hline & Coal & Nuclear & Wind & Photovoltaic \\
\hline Health effects & $0.18-1.39$ & $0.02-0.10$ & $0.02-0.05$ & $0.06-0.09$ \\
\hline Hypoth. accidents & - & $0.01-0.07$ & - & - \\
\hline \multicolumn{5}{|l|}{ Environmental effects: } \\
\hline Forest & 0.19 & - & - & - \\
\hline Noise & - & - & $0-0.01$ & \\
\hline Other plants and animals & 0.02 & - & & \\
\hline Materials & $0.05-0.08$ & - & - & - \\
\hline Depletion of natural resources & $0-0.03$ & $0-0.03$ & - & - \\
\hline Public research and development & $0-0.06$ & $0-0.45$ & $0-0.34$ & $0-1.25$ \\
\hline Public subsidies & $0-0.58$ & $0-0.03$ & - & - \\
\hline Total amount & $0.44-2.35$ & $0.03-0.68$ & $0.02-0.40$ & $0.06-1.34$ \\
\hline
\end{tabular}

Note: ${ }^{a} 1 \mathrm{Pf}(1 / 100 \mathrm{DM})$ is approximately equivalent to USe 0.6 .

avoids this difficulty, is to divide the future annual $R \& D$ expenditure by the annual electricity production of a certain technique to get specific costs.

Future technology related research and development spending is difficult to foresee, however. For coal and nuclear power stations it is assumed that the specific R\&D expenditure per kilowatt hour for the year 1988 ie R\&D expenditure divided by the electricity generated in 1988, will remain constant in the near future. With this assumption the external costs for research and development are $\mathrm{Pf} 0.06 / \mathrm{kWh}$ fl for coal power stations and $\mathrm{Pf} 0.45 / \mathrm{kWh}$ el for nuclear power stations. New systems like wind and photovoltaics produce only a very small amount of electricity at present, so the application of the approach described above would lead to extremely high external costs of renewable energy systems for $R \& D$; in other words, new innovative systems would be handicapped. This problem could be diminished by using the expected future electricity production of new systems instead of the present value.

Of course, there are other problems connected with these approaches eg it is often difficult to allocate expenditure accurately to a specific group of electricity generating systems or - as in the case of fundamental research - impossible. Furthermore, it should be considered that currently R\&D subsidies are granted by the German government without expecting a repayment. So another approach would be to continue with the current research policy and to regard $R \& D$ expenditure as a provision for the future without internalizing it as external costs.

\section{Public subsidies}

If public subsidies are regarded as external costs, the subsequent demand for internalization implies that the subsidies should be cancelled. However, if public subsidies are granted to compensate for an external benefit, they should not be regarded as external costs. So the question of whether subsidies are external costs depends on the question of whether subsidies are justifed or not. If not, they should be cancelled anyway. Public subsidies for coal related to electricity generation amounted to DM772 million in FR Germany in 1988, which can be transformed into specific costs of $\mathrm{Pf} 0.58 / \mathrm{kWh}_{\mathrm{cl}}$.

\section{External costs of electricity generating systems}

The results of a first estimate of the external costs of quantifiable external effects of electricity generation from modern coal, nuclear, wind and photovoltaic power plants for FR Germany are shown in Table 3.

Forest damage, damage to animals, plants and materials, health effects, accidents at nuclear power plants, public research and development expenditure, public subsidies and the depletion of natural resources have been considered. Health effects are taken into account not only during power plant operation, but also during power plant construction and dismantling and throughout the whole fuel cycle. Not considered are, inter alia, the human suffering caused by accidents and illness and the effects of climatic changes due to the release of greenhouse gases. It has to be pointed out that the data quoted, especially the results of forests damage, health effects and the effects of accidents at nuclear power plants, are based on very rough estimates of the damage functions and the monetary value of the damage.

The main components of external costs in coal power stations are subsidies and the influence of air pollution on human health and forest damage. On the other hand, research and development expendi- 
Table 4. Data for coal and nuclear power stations.

\begin{tabular}{|c|c|c|c|}
\hline & Unit & Coal power station & Nuclear power station \\
\hline Lifetime & Years & 35 & 40 \\
\hline Construction time & Years & 4 & 6 \\
\hline Net electricity output & MW & 626.9 & 1258 \\
\hline Investment ${ }^{2}$ & DM $88 / \mathrm{kW}$ & 2117 & 3784 \\
\hline Dismantling costs & DM88/kW & 0 & 400 \\
\hline Supervision after closure & DM88/MW year & 0 & 3975 \\
\hline Fixed maintenance and repair costs & DM88/kW year & 40.5 & 41.5 \\
\hline Insurance & DM88/kW year & 5.1 & 12.2 \\
\hline Staff requirement & Number & 220 & 300 \\
\hline Personnel costs & DM88/kW person & 71000 & 86000 \\
\hline Other fixed costs ${ }^{b}$ & DM88/kW year & 11.1 & - \\
\hline Flue gas purification & DM88/MWh & 1.2 & - \\
\hline Other variable costs & DM88/MWh & 1.8 & 1.0 \\
\hline Net efficiency & $\%$ & 37.6 & 31.4 \\
\hline Fuel costs & DM88/MWh & 106.1 & 29.8 \\
\hline
\end{tabular}

Notes: ${ }^{a}$ Including interest during building period and customer contributions,

${ }^{b}$ Catalytic converter costs.

ture is the main item for the other three electricity generating systems.

\section{Comparison of social costs of different electricity generating systems}

To answer the question of whether the cost relationship between the electricity generating systems under review changes appreciably when the external costs are taken into account, the overall (external and internal) costs have to be considered.

The basic assumptions (costs and technical parameters) necessary to calculate the internal electricity generation costs per kilowatt hour for each of the different systems are shown in Tables 4 and 5. For wind and photovoltaic systems future investment costs are set far below current values in order to allow for the effects of possible future progress in development and production. Future reductions in investments for coal and nuclear power stations are not allowed for. Real price increases of $0.5 \%$ pa for domestic coal and $2 \%$ pa for uranium are assumed.

For the calculation of specific electricity costs per kilowatt hour a real discounting rate of $4 \%$ pa is taken. The calculation is based not on the depreciation period for tax purposes but on the technical service life. Taxes are not taken into account.

For carrying out a consistent comparison, it is necessary to define a supply task, that has to be met by the different electricity generation systems. Two supply tasks with 4000 full load hours per year and 7000 full load hours per year are fixed. With wind and photovoltaic systems alone (without storage) it is not possible to fulfil these tasks, as the demand cannot be met when the wind is not blowing or the sun is not shining. During those periods a conventional generating system has to be used. To take the additional costs for the provision of the conventional system into account, so-called back up costs have to be added to the internal costs of wind and solar generators.

The probability that wind and sun will contribute

Table 5. Data for wind converter and photovoltaic systems.

\begin{tabular}{|c|c|c|c|c|c|c|}
\hline & & \multicolumn{2}{|c|}{ Wind converter } & \multicolumn{2}{|c|}{ Photovoltaic } & \multirow[b]{2}{*}{2200} \\
\hline & & 1988 & 2000 & 1988 & 2000 & \\
\hline Lifetime & Years & 15 & 15 & 30 & 30 & 30 \\
\hline Construction & Years & 0.4 & 0.4 & 0.1 & 0.1 & 0.1 \\
\hline Net electricity output & $\mathrm{kW}_{\mathrm{el}}$ & 200 & 200 & 10 & 10 & 10 \\
\hline Investments ${ }^{\mathrm{a}}$ & DM88/kWnet & 3216 & 1950 & 27697 & 13402 & 6194 \\
\hline \multicolumn{7}{|l|}{ Fixed maintenance } \\
\hline and repair costs & DM88/kW year & 64.8 & 39.5 & 213.0 & 172.0 & 152.0 \\
\hline Other variable costs & DM88/MWh & 0.0 & 0.0 & 0.0 & 0.0 & 0.0 \\
\hline Load factor & $\%$ & $17.4^{\mathrm{b}}$ & $18.3^{c}$ & $13.2^{\mathrm{d}}$ & $13.2^{\mathrm{d}}$ & $13.2^{\mathrm{d}}$ \\
\hline Fuel costs & DM88/MWh & 0.0 & 0.0 & 0.0 & 0.0 & 0.0 \\
\hline
\end{tabular}


Table 6. Cost comparison in Pf 88 per kilowatt hour ( 7000 full load hours of whole system, excluding tax).

\begin{tabular}{lcllc}
\hline & Internal costs & Back up costs & External costs & System costs \\
Nuclear energy & 7.12 & 0.07 & $0.03-0.68$ & $7.2-7.9$ \\
Coal & 13.84 & - & $0.44-2.35$ & $14.3-16.2$ \\
Wind & 23.29 & 2.02 & $0.03-0.41$ & $25.3-25.7$ \\
Wind 2000 & 13.39 & 2.05 & $0.03-0.41$ & $15.5-15.9$ \\
Photo & 157.82 & 1.44 & $0.07-1.35$ & $159.3-160.6$ \\
Photo 2000 & 81.69 & 1.44 & $0.07-1.35$ & $83.2-84.5$ \\
Photo 2020 & 47.59 & 1.44 & $0.07-1.35$ & $49.1-50.4$ \\
\hline
\end{tabular}

Note: ${ }^{a}$ Including external costs of back up system.

Table 7. Cost comparison in Pf 88 per kilowatt hour ( 4000 full load hours of whole system, excluding tax).

\begin{tabular}{lcllc}
\hline & Internal costs & Back up costs & External costs & System costs \\
Nuclear energy & 10.14 & 0.12 & $0.03-0.68$ & $10.3-10.8$ \\
Coal & 15.94 & - & $0.44-2.35$ & $16.4-18.3$ \\
Wind & 23.29 & 4.00 & $0.04-0.42$ & $27.3-27.7$ \\
Wind 2000 & 13.39 & 4.03 & $0.04-0.42$ & $17.5-17.8$ \\
Photo & 157.82 & 3.41 & $0.08-1.36$ & $161.3-162.6$ \\
Photo 2000 & 81.69 & 3.41 & $0.08-1.36$ & $85.2-86.5$ \\
Photo 2020 & 47.59 & 3.41 & $0.08-1.36$ & $51.1-52.4$ \\
\hline
\end{tabular}

Note: ${ }^{a}$ Including external costs of back up system.

to the generation of electricity during the peak demand periods is greater than zero. In this study a capacity effect of $5 \%$ of the installed capacity for wind converters and $7.5 \%$ for photovoltaic systems is assumed. In nuclear power stations account is taken of the fact that because of the high unit output a higher reserve is required than for the smaller coal units. The calculation of back-up costs is described in Friedrich et al. ${ }^{16}$

Tables 6 and 7 contain the electricity generation, back up and external costs and the total costs. It can be seen that quantifiable external costs play a subordinate role in comparison with the costs already internalized in the electricity prices. Even with external costs taken into account there is no change in the current order of cost effectiveness of the systems under review. Photovoltaic systems will remain uneconomic, even with extensive cost reductions, well into the next century. By the year 2000 wind energy costs will have reached the same level as those for power stations using domestic coal (Figure 1). This is due above all to the assumed reduction in investment costs and only to a small extent to the internalization of the external costs of coal power stations. Electricity generation costs of power stations not considered here which use oil, natural gas or imported coal are currently considerably lower than the costs for electricity generation from domestic coal and wind energy.

Of course, it must be kept in mind that this analysis only covers external effects that can be quantified and monetized. So no statement can be made as to whether the consideration of all external effects changes the competitive position of the systems investigated. The statement above only refers to quantifiable external effects.

\section{Conclusions}

In principle, internalizing external costs may reduce misallocations of limited economic resources. Of course, all branches of the economy should be

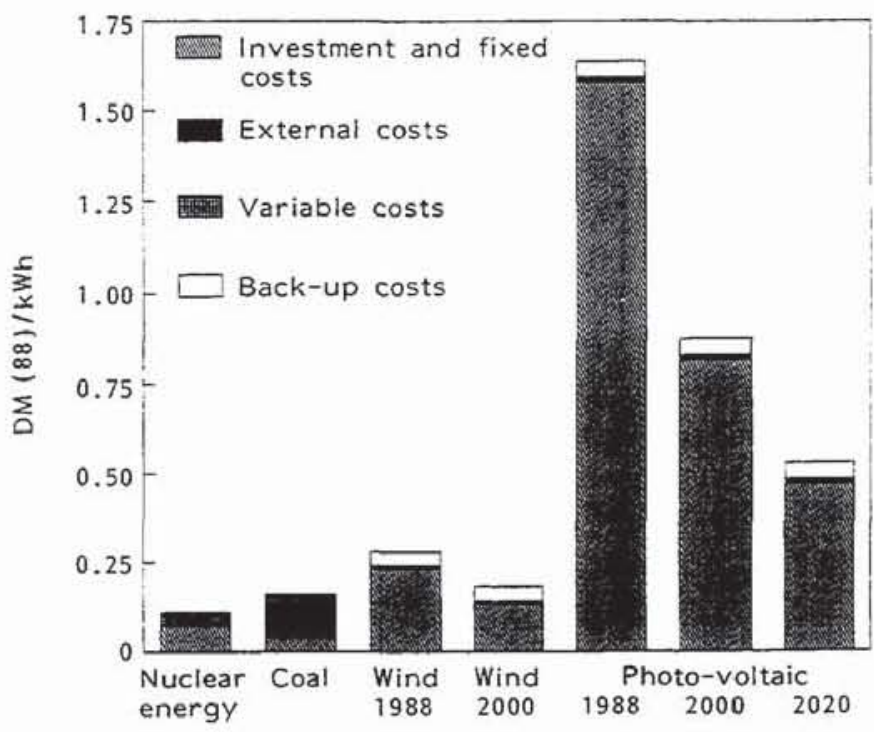

Figure 1. Electricity generation costs including external costs (upper limit) for 4000 full load hours of the supply system. 
considered within this process, as the consideration of electricity production alone may also lead to non-optimal decisions.

The main problem that hampers the application of the concept of internalizing external costs, is the quantification and monetization of external effects, as methods for the quantification as well as doseresponse relationships and damage functions are uncertain, doubtful controversial or totally missing.

If available cost estimates are used in spite of large uncertainties, the resulting external costs do not significantly change the present competitive position of electricity production from coal, nuclear power, photovoltaics and wind.

In particular, with today's knowledge it is not possible to prove that external costs are at least of such an order of magnitude that renewable energy systems which are far from being economic would become economically viable. Consequently, a decision to use such renewable energy systems has still to be the result of the subjective balancing of pros and cons including the consideration of external effects that cannot be quantified or monetized. However, if the internal costs of different systems are close together (like Wind 2000 and domestic coal), the external costs may become decisive.

It is not surprising that quantifiable external costs are rather small. The reason is that the significant external effects identified have always been internalized in the costs by proper instruments such as standards and regulations. For instance, forest damage in Germany led to regulations that achieved a substantial decrease in emissions. These regulations were enacted without prior knowledge of the exact relationship between emissions and damage and without the existence of reliable estimates of the external costs of forest damage. In many cases it may not be realistic to assume that the monetizing of external effects proves that effects which have been regarded as insignificant have high external costs. On the contrary, in many cases there will be the realization that an external effect causes severe problems first and only then the problem is investigated in detail. In these cases it may be too late to wait for action until external costs are calculated, which limits the usefulness of the external cost approach.

In addition to the quantifiable external effects there may be effects that are not known today and there certainly are effects that are known but cannot be quantified today. An example of the latter are the effects of climatic changes due to the emission of greenhouse gases.

In conclusion, it is not possible to compile a full and reliable quantification of all known external effects caused by electricity production. Consequently, decisions in this field require an evaluation of all - quantifiable and unquantifiable - advantages and disadvantages. Nevertheless it is advisable to expand the share of the quantifiable arguments involved in the decision making process.

${ }^{1}$ Olav Hohmeyer, Social Costs of Energy Consumption, SpringerVerlag, Berlin, Heidelberg, New York, 1989; Olav Hohmeyer. 'Renewables and the full costs of energy', Energy Policy, Vol 20, No 4, April 1992.

${ }^{2}$ R. Friedrich, U. Kallenbach, E. Thöne, A. Voss, H.-H. Rogner and D. Karl, Externe Kosten der Stromerzeugung, VWEWVerlag, Frankfurt/Main, 1989

${ }^{3} \mathrm{Op}$ cit, Ref 1 .

${ }^{4}$ H.-J. Ewers, H.D. Brabänder, H.-M. Brechtel, M. Both, E. Hayessen, B. Möhring, M. Moog, W. Nohl and U. Richter, Zur monetären Bewertung von Umweltschäden, Umweitsbundesamt (UBA), Berlin, UBA Report No 4, 1986.

${ }^{5} \mathrm{~L}$. Wicke, Die ökologischen Milliarden, Kösel-Verlag, Munich 1986.

${ }^{6}$ I. Heinz, Volkswirschaftliche Kosten durch Luftverunreinigung, University of Dortmund, INFU Workshop series, Vol 4, Dortmund, 1980.

${ }^{7}$ Op cit, Ref 5

${ }^{8}$ I. Heinz, 'Zur ökonomischen Bewertung von Materialschäden durch Luftverschmutzung', in Umweltbundesamt, eds, Kosten der Luftverschmutzung, UBA Report 7, Berlin, 1986; op cit, Ref 6. ${ }^{\circ} \mathrm{Op}$ cit, Ref 1.

${ }^{10} \mathrm{U}$. Kallenbach and E. Thöne, Gesundheitsrisiken der Stromerzeugung, Verlag, TÜV Rheinland, Cologne, 1989.

${ }^{11}$ Cited from W.K. Viscusi, 'The valuation of risks to life and health: guidelines for policy analysis', in J.D. Bentkover, ed, Benefits Assessment: The State of the Art, Kluwer, Dordrecht, 1986.

${ }^{12}$ R.P. Burke, D.C. Aldrich and N.C. Rasmussen, Economic Risks of Nuclear Power Reactor Accidents, NUREG/CRP3673, Washington DC, 1984.

${ }^{13} \mathrm{Op}$ cit, Ref 1 .

${ }^{14} \mathrm{Op}$ cit, Ref 2.

${ }^{15} \mathrm{~A}$. Endres, Umwelt-und Ressource ökonomie, Wissenschaftliche Buchgesellschaft, Darmstadt, 1985.

${ }^{16} \mathrm{Op}$ cit, Ref 2. 